
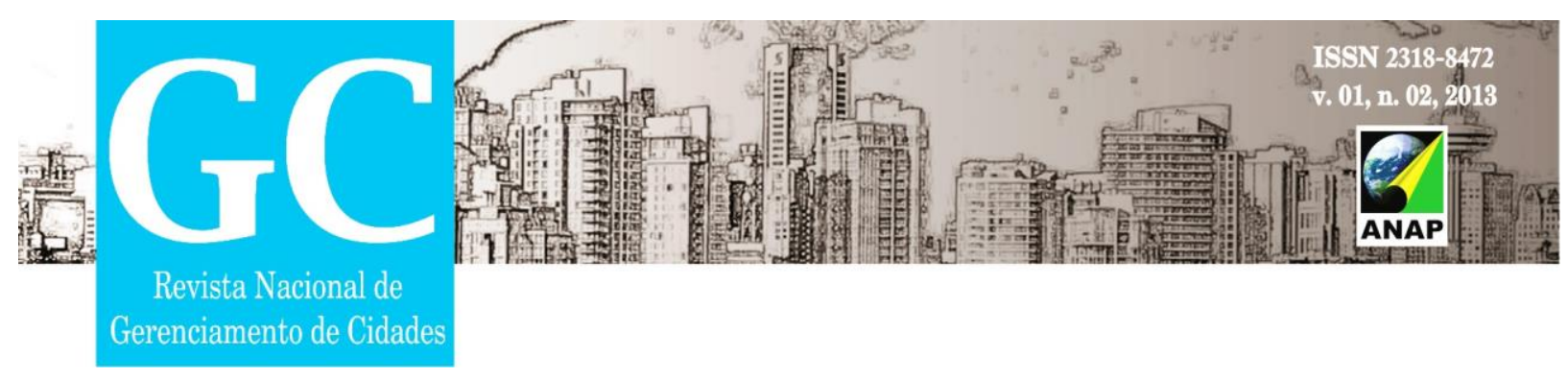

\title{
PLANO DIRETOR MUNICIPAL E INSTRUMENTOS URBANÍSTICOS DE PLANEJAMENTO E GESTÃO URBANOS
}

\author{
Sibila Corral de Arêa Leão Honda ${ }^{1}$
}

Mayara Pissutti Albano ${ }^{2}$

RESUMO: Esta pesquisa busca contribuir para uma análise crítica sobre as ações públicas municipais relativas aos instrumentos urbanísticos de controle e planejamento urbanos. O artigo aborda a política pública local de uma cidade de médio porte, que apoia as decisões de planejamento urbano, identificando seus planos diretores e os instrumentos incluídos, aprovados e regulamentados. Visa-se, dessa forma, constatar como decisões públicas municipais têm sido definidas, embasadas em planos - diretores e setoriais - locais. Para tal, foi elaborado estudo de caso no município de Presidente Prudente, interior do Estado de São Paulo, e foca-se no instrumento 'Concessão de Direito Real de Uso' e seu reflexo na produção do espaço urbano. A metodologia assumida é qualitativa, e baseia-se em aprofundamento teórico e levantamentos documentais. Conclui-se que para a produção de uma cidade mais justa e equitativa, as políticas urbana e habitacional municipais precisam ser revistas, de modo articulado, apresentando diretrizes adequadas e relativas à realidade local, e possibilitando o uso de instrumentos urbanísticos includentes.

Palavras chave: Política Urbana. Habitação de Interesse Social. Expansão Urbana.

1 Graduação em Arquitetura e Urbanismo, Mestrado e Doutorado em Arquitetura e Urbanismo. Docente e Coordenadora do curso de Arquitetura e Urbanismo da Universidade do Oeste Paulista. E-mail: sibila@unoeste.br

${ }_{2}$ Graduação em Arquitetura e Urbanismo, Mestranda. Docente no curso de Arquitetura e Urbanismo da Universidade do Oeste Paulista E-mail: ma.albano@unoeste.br 


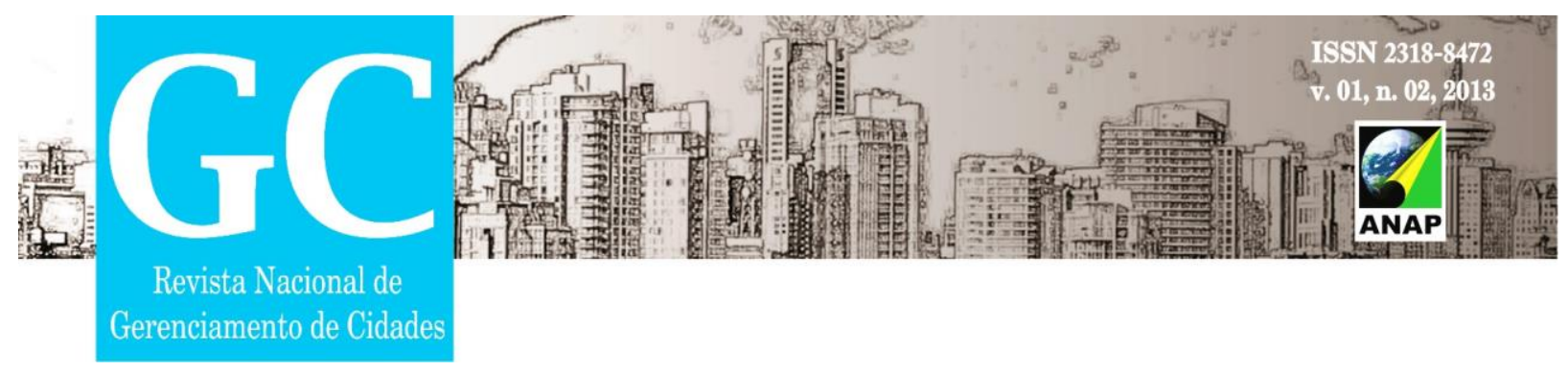

\section{INTRODUÇÃO}

Este trabalho busca discutir o planejamento urbano como elemento estruturador dos Municípios, que embasa o desenvolvimento regional, por meio de políticas urbanas locais que visem a controlar, direcionar e gerir o espaço de cidades. Para tanto, foi executado estudo de caso em uma cidade de porte médio no interior do Estado de São Paulo, o município de Presidente Prudente, verificando a inclusão, a aprovação e o uso de instrumentos urbanísticos em âmbito local junto ao Plano Diretor.

O processo de urbanização acelerado que tem ocorrido no Brasil desde a década de 1940 tem gerado grande déficit habitacional e carência de infraestrutura e serviços urbanos, provocando a diminuição da qualidade de vida nas cidades, atingindo, inclusive as de médio porte.

Seu resultado imediato é a expansão territorial urbana sem regularização legal, ou seja, a ocupação ilegal de glebas não urbanizadas e o adensamento populacional em áreas não adequadas à ocupação, inclusive com o surgimento e crescimentos de favelas.

$\mathrm{E}$, ao mesmo tempo, a construção de habitação de interesse social, no Brasil, também pode ser relacionada diretamente com a expansão urbana, devido à implantação de conjuntos habitacionais nas periferias das malhas urbanas ou além dela, em locais distantes, deficientes em infraestrutura, serviços e equipamentos urbanos (BONDUKI, 1998).

Frente a essa situação são necessárias políticas urbanas articuladas de planejamento e gestão urbanos, relacionados ao uso do solo urbano, à habitação, à infraestrutura, etc., a fim de se estabelecer ambientes urbanos equilibrados e justos.

E, com a Constituição Federal (CF) de 1988, os temas relacionados à política e à gestão urbanas passaram a ter maior destaque em várias esferas institucionais, políticas e sociais, com o fortalecimento do Município, e sua definição como um dos entes federativos. A política de desenvolvimento urbano tornou-se responsabilidade municipal, e 


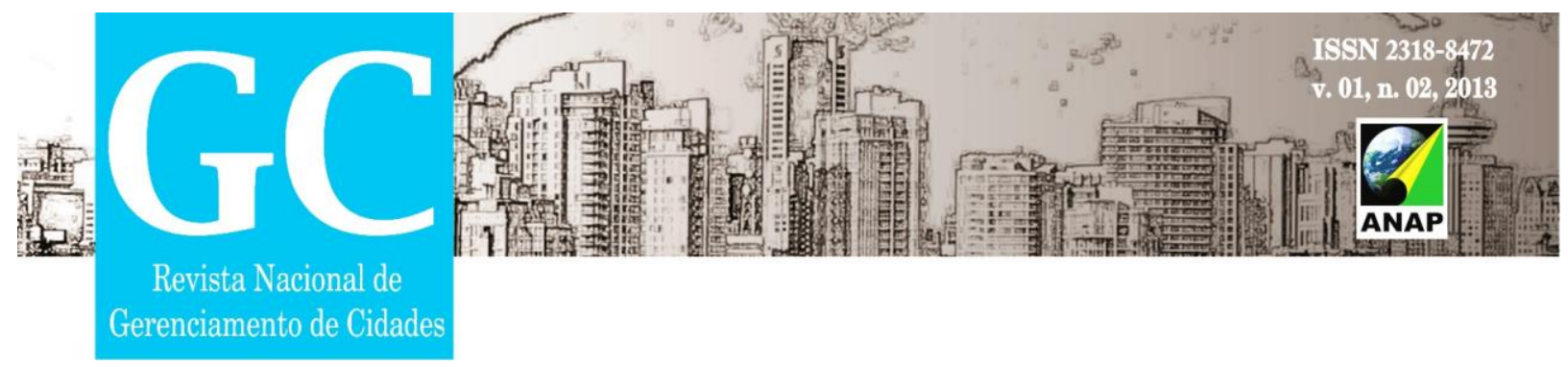

a política habitacional, em teoria, passou a ser central para os Municípios, estratégica quanto ao controle urbano, focando no direito à cidade.

No entanto, muitos municípios não assumiram a postura de utilizar adequadamente os instrumentos urbanísticos propostos na nova Constituição Federal (CF), como a aprovação de Plano Diretor específico ao município.

Em 2001, com a aprovação da Lei Complementar n.10.257 (Estatuto da Cidade), novos instrumentos urbanísticos tornaram-se claros para utilização local, para inclusão nos Planos Diretores municipais. Mas, também não foram incluídos, aprovados e regulamentados adequadamente em diversos municípios brasileiros.

A partir dessa realidade, objetiva-se analisar as ações políticas municipais na cidade de Presidente Prudente, por meio de seus Planos Diretores e legislação específica, identificando alguns instrumentos urbanísticos aprovados e utilizados nesse município, e principalmente o instrumento Concessão de Direito Real de Uso, não incluído na Constituição Federal (CF), não aprovado no Plano Diretor municipal desta cidade, e utilizado pelo Poder Público local.

\section{CONSTITUIÇÃO FEDERAL DE 1988 E POLÍTICAS URBANAS}

Em função do processo de urbanização brasileiro e do déficit de moradia, na década de 1980, junto ao processo de redemocratização brasileiro, foram retomadas discussões sobre reforma urbana, sobre os temas relacionados ao planejamento municipal, e sobre os instrumentos de regulação fundiária e controle de terras urbanas.

Com base nesse movimento, foi incluído na nova Constituição Federal Brasileira um capitulo sobre Política Urbana (art. 182 e 183). A partir de então, o Município passou a ser ente federativo, assim como os Estados e a União, com competências específicas, exclusivas, e comuns.

Segundo o que consta nos artigos 30 e 182, o Município deve legislar sobre os assuntos de interesse local, com obrigação específica sobre o espaço urbano, por meio 


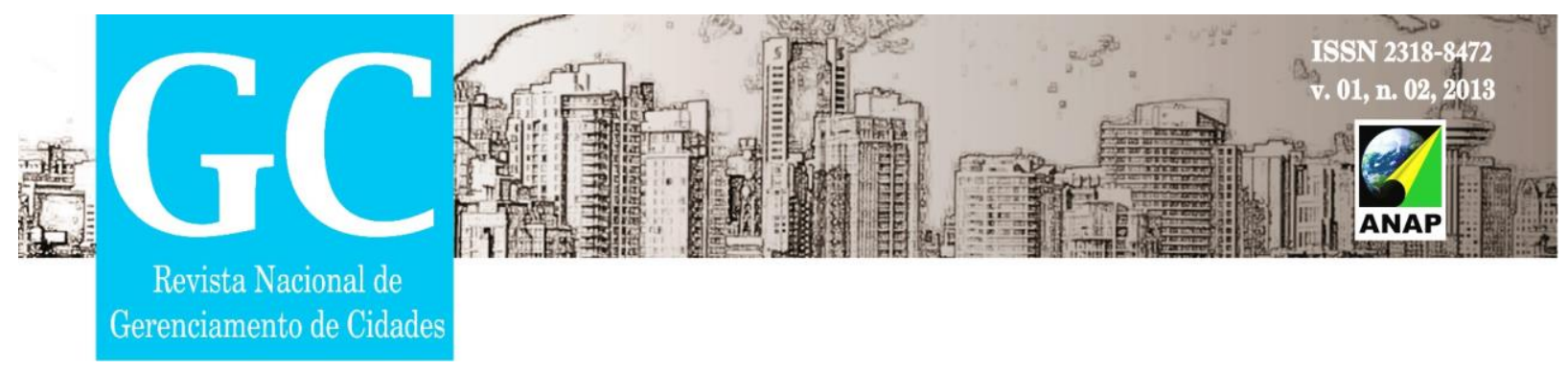

de uma política de desenvolvimento urbano que foque nas funções sociais da cidade, com adequado ordenamento territorial; sendo o Plano Diretor (PD) seu principal instrumento.

O Plano Diretor municipal deve estabelecer diretrizes da política urbana, sendo um conjunto de propostas, de curto, médio e longo prazos, para o desenvolvimento social, econômico, espacial, e de infraestrutura urbana, para todo o Município, e aprovado como por lei municipal (ROLNIK et al, 2004; VILLAÇA, 1999-b).

A Lei Complementar ํo.10.257/2001, denominada Estatuto da Cidade (EC), regulamentou os artigos 182 e 183 da Constituição Federal (CF) de 1988, tendo listado alguns instrumentos urbanísticos de intervenção, gestão, planejamento e controle do território, que poderiam ser incluídos e aprovados nos Planos Diretores municipais. Importante destacar dois desses instrumentos: 'Concessão de Direito Real de Uso' e 'Concessão de Uso Especial para fins de Moradia', este com artigos vetados quando o EC foi sancionado.

A Concessão de Direito Real de Uso é instrumento de utilização pelo Poder Público, remunerado ou não, por tempo certo ou indeterminado, com finalidade de uso de interesse social (SILVA, 2002). Todos os instrumentos, para serem utilizados, devem estar aprovados nos Planos Diretores, além de regulamentados em legislação municipal específica, seguindo a política urbana.

No contexto das políticas públicas, a análise sobre políticas urbanas é fundamental, sendo necessária constante adequação de sua gestão. Para Villaça (1999-a) as políticas urbanas se baseiam nas ações e propostas de ação do Poder Público sobre o ambiente urbano. Alvim, Castro e Zioni (2010) completam que essas ações ocorrem por meio de metas e diretrizes relacionadas às necessidades e demandas sociais no espaço urbano.

\section{POLítICA URBANA E A PRODUÇÃo do ESPAÇO EM PRESIDENTE PRUDENTE}

Presidente Prudente é cidade localizada no Estado de São Paulo, e teve sua base de colonização apoiada na implantação de estrada de ferro, em 1919, e na produção 


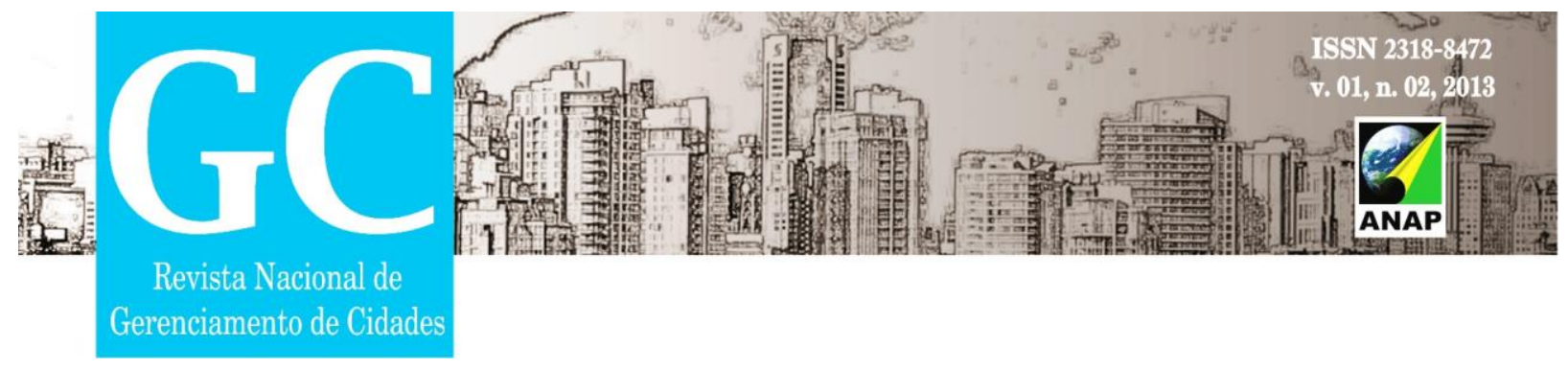

agropecuária. Em 1921, o município foi criado legalmente, representando o centro político e administrativo regional.

Sua estrutura política se formou baseada no coronelismo, reproduzida ao longo dos anos. Segundo Abreu (1996, p. 48), a 'Revolução de 1930', ocorrida no Brasil, não alterou significativamente as práticas políticas prudentinas, sendo que "o coronelismo continuasse sob a roupagem nova do populismo, exercido por uma liderança local que nada mais fazia do que seguir os modelos estadual e federal".

Entre o início da década de 1920 e a primeira metade da década de 1950, em processos cíclicos, a malha urbana de Presidente Prudente apresentou períodos de grande expansão territorial; mas entre a segunda metade da década de 1950 e início da de 1960 percebe-se forte redução dessa realidade, podendo ser identificado por pequeno crescimento espacial urbano.

A partir de então, com a instituição Governo Militar, a cidade de Presidente Prudente foi alvo de alterações sociais, econômicas, políticas e legais significativas, refletindo no processo de estruturação urbana. Verifica-se um crescimento do quadro industrial com ampliação do leque produtivo, aumento da população e desenvolvimento das atividades terciárias.

Em 1968, o Centro de Pesquisas e Estudos Urbanísticos (CPEU), da Faculdade de Arquitetura e Urbanismo da Universidade de São Paulo (FAU-USP), iniciou a elaboração do primeiro Plano Diretor para a cidade - Plano Diretor de Desenvolvimento Integrado (PDDI), segundo metodologia do Serviço Federal de Habitação e Urbanismo (SERFHAU).

Durante as décadas de 1970 e 1980, percebe-se grande expansão territorial urbana, criando grandes vazios no traçado da cidade por longos períodos de tempo; sendo que muitos loteamentos foram abertos fora da malha consolidada, mas somente receberam moradores após serem utilizados para construção de habitação social (HONDA, 2011).

Em relação à aquisição de unidades de habitação de interesse social na cidade, as faixas de renda partiam de três salários mínimos. No entanto, população sem renda ou com renda familiar abaixo desse piso, entre as décadas de 1960 e 1980, recebeu muitos 


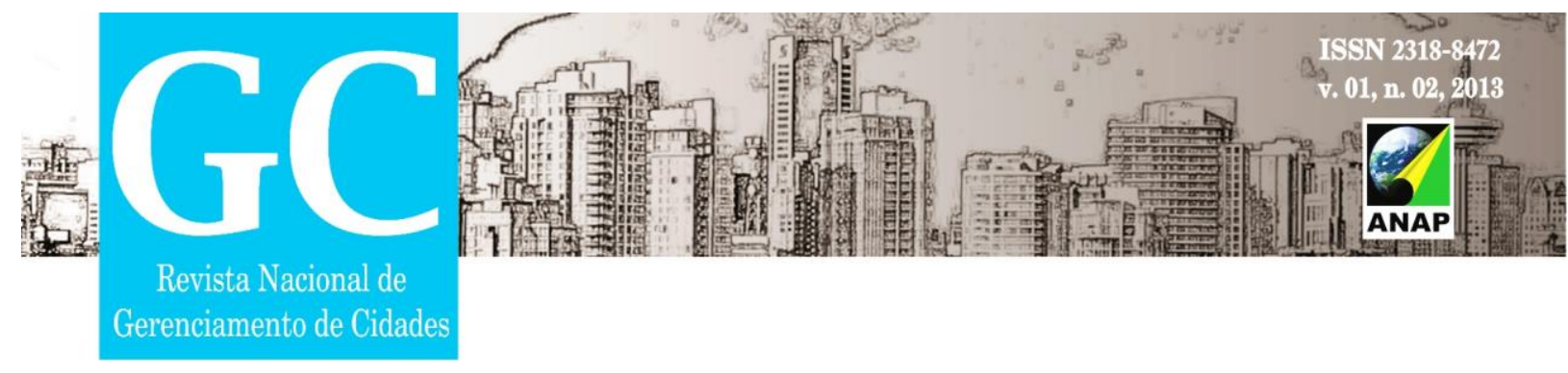

benefícios do Poder Público local por meio de direito de uso e ocupação (verbais) de áreas públicas municipais.

No ano de 1988, foi sancionada a nova Constituição Federal, com inclusão de capítulo específico sobre política urbana e exigência de Plano Diretor municipal. Em 1989, a aprovação da Constituição Estadual paulista, obrigou todos os municípios paulistas, independente de sua população, elaborarem seus planos diretores. Em 1990, foi aprovada a Lei Orgânica de Presidente Prudente.

Nesse mesmo ano, o Poder Público local lançou o Projeto de Lotes Urbanizados e Desfavelamento, buscando a remoção das famílias que habitavam áreas de risco ou irregulares; mas que não se efetivou, pois sua população buscava a urbanização das favelas e a permanência no local, por meio da Concessão do Direito Real de Uso, que não foi aprovada (MARISCO, 2003).

Entretanto, durante a gestão municipal seguinte (1993-1996), ocorreu concessão de direito de uso de 4.013 lotes urbanizados no município, sem participação dos Governos Federal ou Estadual. A construção dos imóveis foi realizada por meio de autoconstrução.

No último ano dessa gestão, foi aprovado Plano Diretor municipal (Lei Municipal no.29/1996), nos moldes da nova Constituição Federal, também tendo por base as discussões relativas ao Projeto de Lei $n^{\circ} .181 / 1989$, que viria a ser aprovado como Estatuto da Cidade. No entanto, muitos instrumentos urbanísticos não foram incluídos no Plano Diretor. Em 2008, foi sancionado o novo Plano Diretor municipal (Lei Municipal $\left.n^{\circ} .151 / 2008\right)$.

A expansão urbana de Presidente Prudente tem demonstrado o maior interesse nas áreas a sul para loteamentos e condomínios das elites, e a oeste e norte para as camadas de menor poder aquisitivo. O processo de crescimento com manutenção de grandes vazios urbanos tem permanecido. 


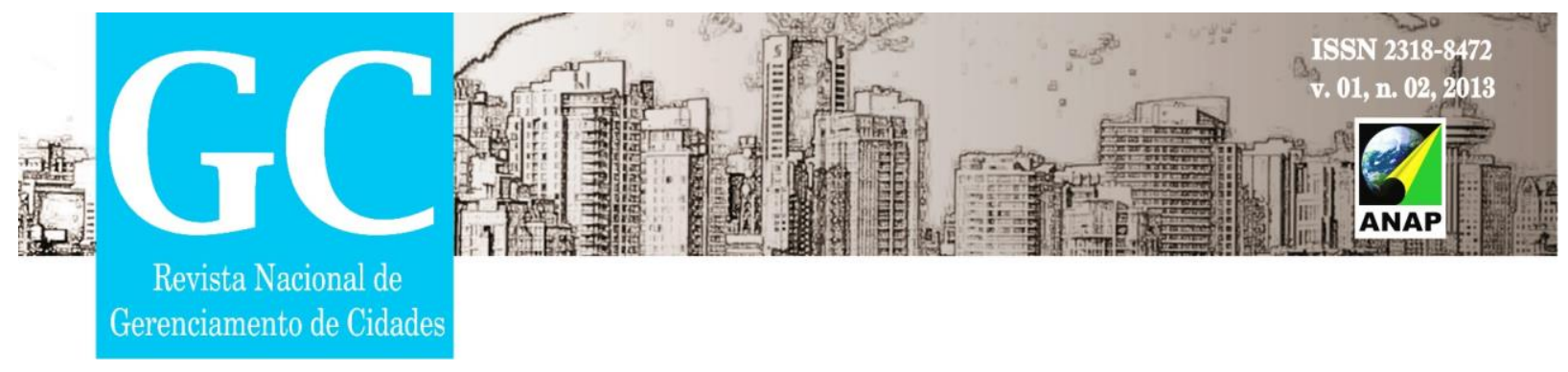

\subsection{PLANOS DIRETORES MUNICIPAIS}

Presidente Prudente apresentou, até o momento, três Planos Diretores. O primeiro denominado Plano Diretor de Desenvolvimento Integrado (PDDI), com metodologia especificada pelo Serviço Federal de Habitação e Urbanismo (SERFHAU), foi elaborado em 1968 e aprovado em 1973.

Segundo Blanc (2012), o planejamento municipal e seus planos diretores das décadas de 1960-1970-1980 tinham como característica sua desvinculação à administração municipal, sendo sua função apenas de orientação técnica. O PDDI de Presidente Prudente ficou em vigor até a década de 1990, mas sem diretrizes observadas, cuja neutralidade técnica mostrou-se ineficaz.

Após a Constituição Federal (CF) de 1988, e devido às mudanças legais e de competência dos Municípios brasileiros, em 1990, foi sancionada a Lei Orgânica de Presidente Prudente, e, em 1996, aprovado o novo Plano Diretor municipal (Lei Municipal $n^{\circ}$.29/1996), à luz do capítulo de Política Urbana da nova CF, visto como instrumento da atuação municipal de planejamento e gestão do espaço urbano, cuja função é sistematizar o desenvolvimento físico, econômico e social (BLANC, 2012).

Entre as políticas setoriais definidas, na seção sobre a política habitacional constam diretrizes gerais de ação pública, que, no entanto, não foi objeto de detalhamento e nem posteriormente de legislação específica. Do conjunto dos instrumentos previstos, foram aprovados apenas o zoneamento, o parcelamento ou edificação compulsórios, e o imposto predial e territorial urbano (IPTU) progressivo no tempo; dos quais somente o zoneamento foi alvo de legislação específica (Lei Complementar Municipal $\left.n^{\circ} .31 / 1996\right)$.

Em relação aos instrumentos urbanísticos, Mattos (2002, p.41) afirma que deveriam "ser utilizados pelos Municípios de forma combinada, de maneira a promover não apenas a regulação normativa dos processos de uso, desenvolvimento e ocupação do solo urbano, mas especialmente para induzir ativamente os rumos de tais processos". 


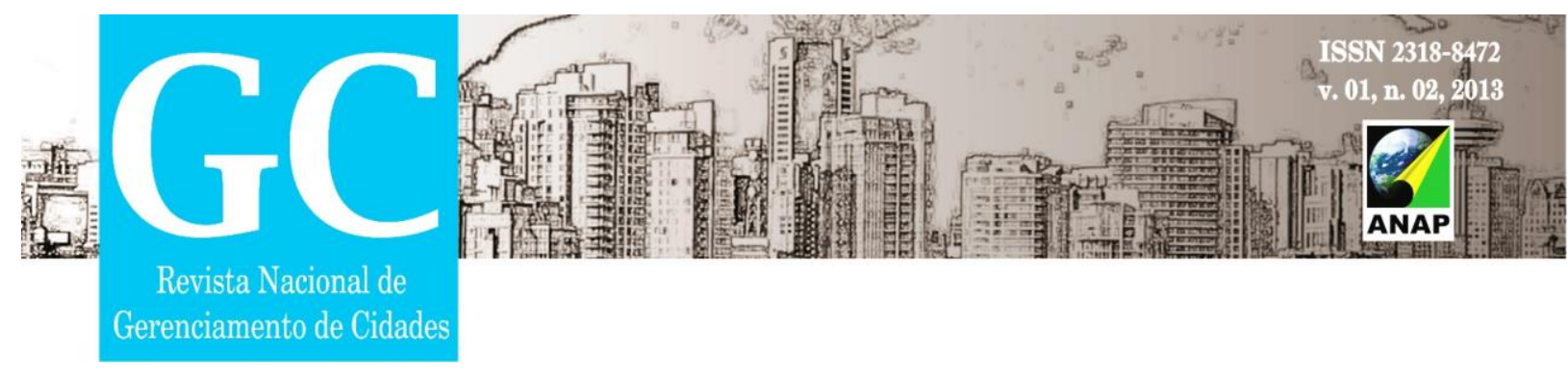

No ano de 1998, foi instituída a primeira lei municipal que trata de Zonas Especiais de Interesse Social (Lei Complementar Municipal $n^{\circ} .53 / 1998$ ), mas que não mapeou ou definiu as áreas passíveis de aplicação desse instrumento. Esta lei entregou aos proprietários imobiliários urbanos o direito de requerer junto à Prefeitura a alteração do zoneamento de sua área para ZEIS.

Em 2001, foi sancionada a Lei Federal nº.10.257/2001 (Estatuto da Cidade), que regulamenta os artigos 182 e 183 da Constituição Federal. Apesar das maiores possibilidades de aplicação de instrumentos urbanísticos para controle, planejamento e gestão das cidades, o município de Presidente Prudente não assumiu a posição de revisão do Plano Diretor.

No entanto, nova lei de zoneamento do solo urbano (Lei Complementar Municipal $\mathrm{n}^{\circ} .128 / 2003$ ) foi aprovada em 2003, com inclusão de dois outros instrumentos urbanísticos, não definidos no Plano Diretor: o Estudo de Impacto de Vizinhança (EIV) e a Outorga Onerosa do Direito de Construir.

Somente em 2007 ocorreu o processo de discussão e revisão do Plano Diretor municipal, tendo sido aprovado no início de 2008 (Lei Municipal n.151/2008). Esse novo Plano não apresenta objetivos, diretrizes ou estratégias de desenvolvimento, e, mais uma vez, não identifica áreas passíveis de aplicação dos instrumentos urbanísticos aprovados, sendo que estes são: parcelamento ou edificação compulsórios; IPTU progressivo, direito de preempção, direito de superfície, outorga onerosa do direito de construir.

No novo Plano Diretor, ocorreu a repetição da política habitacional do Plano anterior, e, da mesma maneira, não faz menção a ZEIS, deixando que esse assunto fosse tratado apenas na lei de zoneamento de uso e ocupação do solo urbano, que mantém a indicação do proprietário para alteração do zoneamento de acordo com seus interesses particulares. Apesar do novo Plano ter incorporado alguns instrumentos urbanísticos, observa-se que a maioria deles não foi regulamentada, ficando a produção do espaço urbano à mercê do mercado privado de terras. 


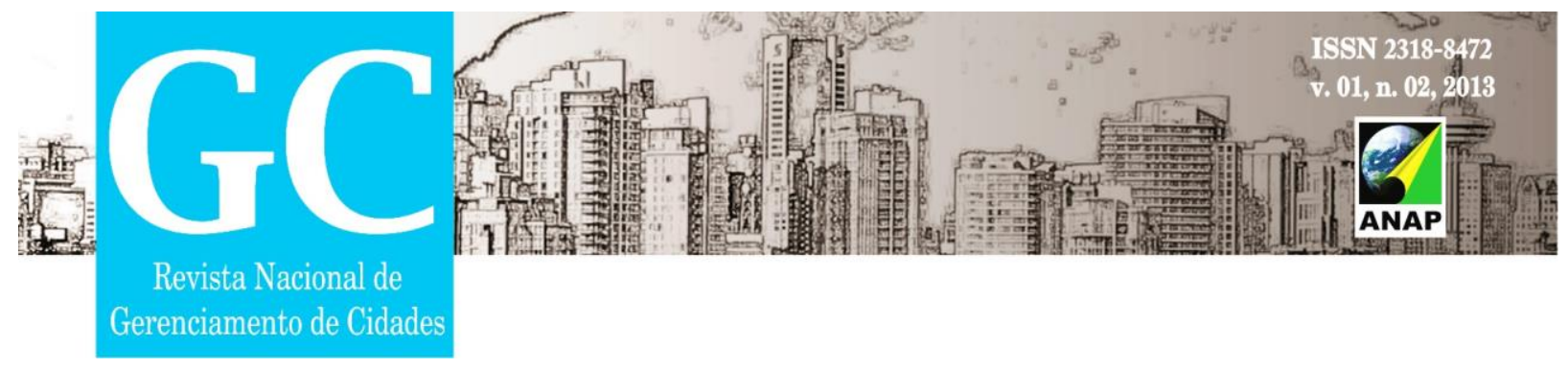

\subsection{INSTRUMENTO URBANÍSTICO CONCESSÃO DE DIREITO REAL DE USO}

Conforme dito, em Presidente Prudente, a Prefeitura Municipal, durante os anos de 1993 a 1996, concedeu direito de uso de 4.013 lotes urbanizados, em seis loteamentos. Esses se localizam na franja urbana ou além da malha, no limite do perímetro urbano, todos na região norte do município, sendo eles: Terceiro Milênio, Humberto Salvador, Morada do Sol, Brasil Novo, Belo Galindo e Primavera, com 160, 1.330, 472, 1.250, 671 e 130 unidades respectivamente.

A ausência de aprovação do instrumento em alguma lei municipal não limitou o Poder Público local a utilizá-lo, reforçando a visão populista do Governo Municipal, mas que possibilitou grande redução do déficit habitacional urbano nessa cidade; principalmente quando se verifica que a população urbana em 2000 (Censo IBGE 2000) era de 185.229 pessoas.

A concessão foi dada por meio de autorização do Poder Executivo municipal, segundo transferência de domínio sem contrapartida financeira das áreas a famílias cadastradas, com renda de até quatro salários mínimos, com residência fixa no município há mais de três anos, sendo definidos os beneficiários por sorteio. Havia a obrigação de construção no lote adquirido em prazo máximo de dois anos, sob pena de perda do direito à área.

No entanto, a Prefeitura Municipal não possui cadastros atualizados relacionando a população beneficiada e os atuais possuidores dos lotes. Apesar de ter sido utilizado instrumento urbanístico de grande utilidade social, voltado à população carente para habitação de interesse social, o referido instrumento não foi incluído formal e legalmente na política habitacional municipal, no Plano Diretor aprovado posteriormente.

\section{CONSIDERAÇÕES FINAIS}




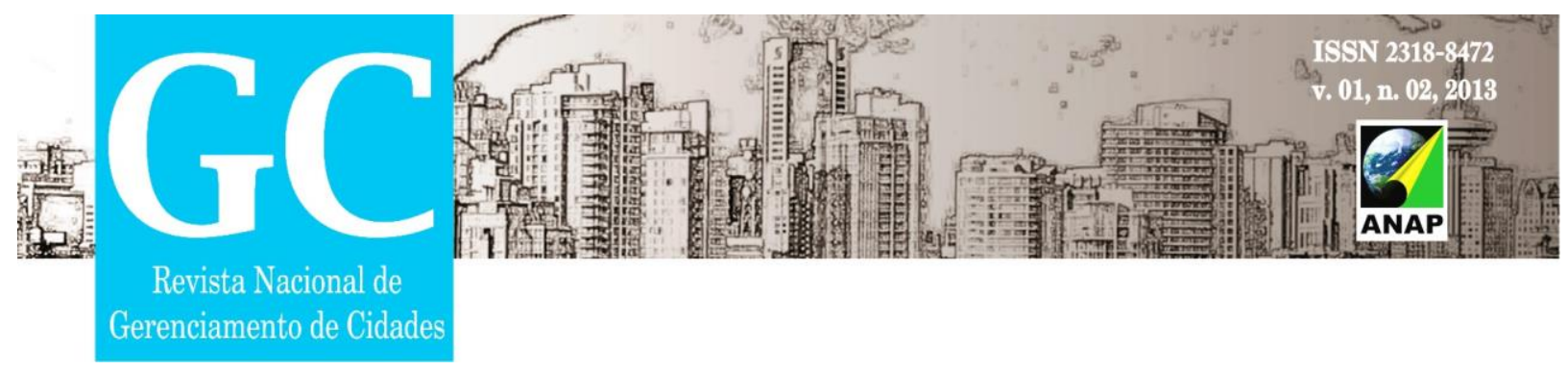

Este trabalho buscou verificar a realidade sobre a ação do Poder Público municipal por meio de políticas urbanas e diretrizes de controle e planejamento do espaço urbano tendo como estudo de caso a cidade de Presidente Prudente, no interior do Estado de São Paulo.

Por meio de análises dos Planos Diretores municipais e a legislação complementar, pode-se constatar que a política pública local implementada não trata adequadamente dos instrumentos urbanísticos, resultando em descompasso entre as possibilidades de planejamento e gestão urbanos; ou seja, é possível identificar a falta de controle sobre o espaço e o processo de expansão territorial.

Observa-se, assim, que as ações do Governo local não refletem as políticas definidas legalmente, e que muitas dessas ações resultam de definições pessoais e populistas; cujo município carece de uma política urbana inclusiva, clara, e que trate satisfatoriamente dos instrumentos do Estatuto da Cidade, visando a uma cidade mais justa. Verifica-se claramente que o Poder Público local cede ao capital imobiliário as diretrizes de ação política.

\section{REFERÊNCIAS}

ABREU, Dióres Santos. Poder Político Local no Populismo: Presidente Prudente (SP) 1928-1959. Presidente Prudente: Impress, 1996.

ALVIM, Angélica Tanus Benatti.; CASTRO, Luiz Guilherme Rivera; ZIONI, Silvana Maria. Avaliação de políticas urbanas. In: ALVIM, Angélica Tanus Benatti.; CASTRO, Luiz Guilherme Rivera (org). Avaliação de políticas urbanas - contexto e perspectivas. São Paulo: UPM/MackPesquisa/Romano Guerra Editora, 2010.

BLANC, Priscila Ferreira. Plano Diretor urbano \& função social da propriedade. 9ạ.reimp. Curitiba: Juruá, 2012.

BONDUKI, Nabil. Origens da habitação social no Brasil. São Paulo: Estação Liberdade, 1998. 


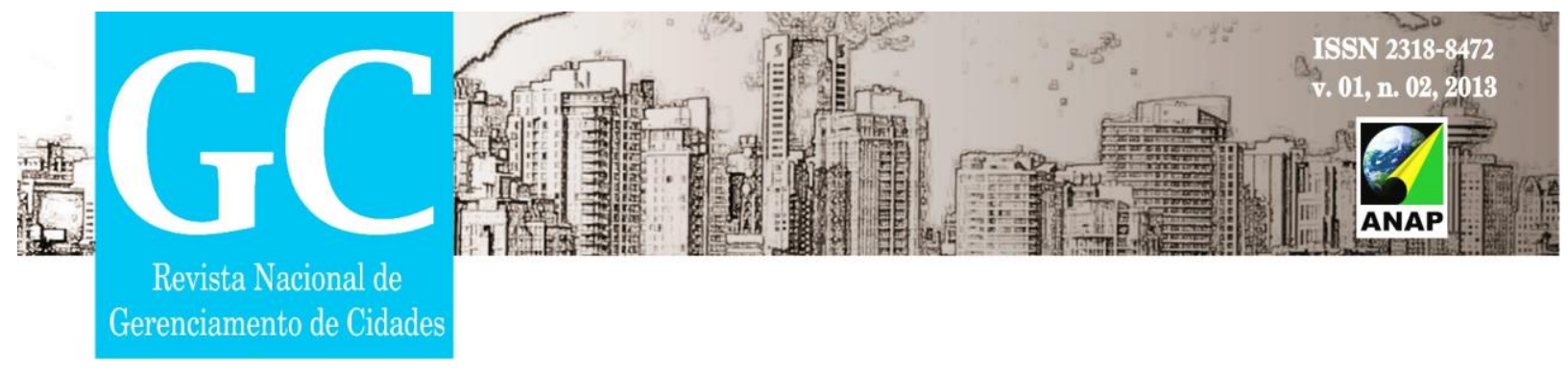

HONDA, Sibila Corral de Arêa Leão. Habitação de Baixa Renda como Produto do Capital - o Programa de Arrendamento Residencial (PAR) em Presidente Prudente. São Paulo: FAU/UPM, 2011. Tese (Doutorado).

MARISCO, Luciane Maranha de Oliveira. A norma e o fato: abordagem analítica da segregação sócio-espacial e exclusão social a partir dos instrumentos urbanísticos. Presidente Prudente: FCT-UNESP, 2003. Tese (Doutorado).

MATTOS, Liana Portilho. Estatuto da Cidade comentado. Belo Horizonte: Mandamentos, 2002.

ROLNIK et al. Plano Diretor Participativo - guia para a elaboração pelos municípios e cidadãos. Brasília: CONFEA/Ministério das Cidades, 2004.

SILVA, Tiago Gonçalves. A concessão de direito real de uso e a experiência do Recife. In: 2․ Congresso de Direito Urbanístico. Porto Alegre. 2002.

SPOSITO. Eliseu Savério. Produção e apropriação da renda fundiária urbana em Presidente Prudente. São Paulo: FLCH/USP, 1990. Tese (Doutorado).

SPÓSITO, Maria Encarnação Beltrão. 0 'chão' em Presidente Prudente: a lógica da expansão territorial urbana. São Carlos: IGCE/UNESP, 1983. Dissertação (Mestrado).

VILLAÇA, Flávio. Uma contribuição para a história do planejamento urbano no Brasil. In: DÉAK, C; SCHIFFER, S.R (orgs). O Processo de Urbanização no Brasil. São Paulo, EDUSP, 1999 (1999-a).

VILLAÇA, Flávio. Dilemas do Plano Diretor. In Fundação Prefeito Faria Lima - Cepam (org) O município no século XXI: cenários e perspectivas. São Paulo: Editora Especial 1999. (1999-b). 